\title{
Designing Stereoscopic Animation for Bromo Tengger National Park Virtual Tour as Alternative for Conservation Education in Pandemic Era
}

\author{
Stormy Yudo Prakoso ${ }^{1, *}$, Banung Grahita ${ }^{2}$ \\ ${ }^{1}$ Student, Bandung Institute of Technology, Indonesia \\ ${ }^{2}$ Lecturer, Bandung Institute of Technology, Indonesia \\ *Corresponding author. Email: stormyyudo@gmail.com
}

\begin{abstract}
The need for travelling has become a primary need for Indonesian people. However, Covid-19 pandemic that is currently happening gives negative impact on the tourism sector. The government is forced to limit tourism activities in many tourism destinations, especially in districts or cities with high covid-19 cases. One alternative way to provide a traveling experience without having to be in the actual destination is using a virtual tour. Virtual tour is a technology that increases situational awareness and the ability to see, and captures and analyzes virtual data to users. Virtual tours are usually used to give the experience of "being" in a place by simply looking at the screen, without having to be in the actual destination. Stereoscopic is a technique of presenting a content by giving the illusion of depth and pop-out in 2-dimensional images. Generally, we often see the stereoscopic technology in 3D Cinemas and 4D Rides. In 3D cinema, stereoscopic films are presented using a special screen with a special projector that can show side-by-side images simultaneously, with the 3D special glasses for enjoying the content perfectly. With the combination of virtual tour and stereoscopic technology, it is expected that it can provide the same experience as an actual experience. To do this research, the authors use design thinking method, by using the natural tourism Bromo Tengger National Parks as a case study area. The results of this study are expected to be consideration and used by the stakeholders as an alternative way of encouraging sectors affected by Covid-19, especially tourism.
\end{abstract}

Keywords: Virtual Tour, Stereoscopic, 3D Animation, Pandemic, Covid-19

\section{INTRODUCTION}

The case of the corona virus in Indonesia has been going on for quite a long time since it was first announced by President Joko Widodo on March 2, 2020. Since then this pandemic has quickly spread to all regions in Indonesia. COVID-19 is an infectious disease caused by a type of coronavirus that was first discovered in Wuhan, China, in December 2019. This virus is now turn into a pandemic that is happening in many countries around the world. To reduce the number of cases of the spread of COVID-19, the Government of Indonesia has implemented several policies to suppress the spread of COVID-19, one of which is Large-Scale Social Restrictions, as previously regulated in Law number 6 of 2018 concerning Quarantine. However, until now the cases are still increasing, and have not shown any signs to stop.

The spread of COVID-19 has had a hard impact not only on economic activities and the transportation sector but also on the tourism industry. The total number of confirmed cases of COVID-19 in Indonesia is 2.57 million as of July 12, 2021 [1]. This number continues to increase from day to day as evidenced by the shape of the curve that tends to continue to climb. The existence of this pandemic has caused a significant decrease the number of local and foreign tourists. Of course causes the tourism industry to suffer considerable losses due to the closure of access for foreign tourists and the enactment of the policy of closing the tourist attraction itself. 
The need for travel is no longer a tertiary or secondary need, but has become a primary need for the people of Indonesia. This need requires us to think creatively on how to still be able to travel even though activity restrictions are being imposed. One of the innovations of traveling by utilizing technology is a virtual tour. Virtual Tour is a content that presents the experience of traveling to explore a tourist destination without having to be present at the actual location. With Virtual Tour, tourists can go to tourist destinations using their gadgets at home.

In East Java (Indonesia), the one of the most popular tourist location for local and foreign tourists is Bromo Tengger who are in the area Bromo Tengger National Park. As one of the ten priority tourist destinations in Indonesia, Bromo Tengger National Park presents a beautiful mountainous natural atmosphere, sunrises directly from the highlands, and other exotic hillside views become an extraordinary attraction for tourists. The phrase "Exocitc Nature on The Ancient of Java" is the branding of Bromo National Park, this is very appropriate because Bromo Tengger National Park is an area with a very unique diversity of ecosystems and a wealth of germplasm that blends with the culture of the local community. The attractiveness of Bromo Tengger National Park is what makes the Indonesian government agree to establish it as one of the ten priority tourist destinations in Indonesia.

With an area of 50,276.20 ha, Bromo Tengger National Park is a life support as well as a home for the flora and fauna in it. There are a total of 1,025 types of flora consisting of 260 medicinal plants/ornamental plants, 226 belonging to the Orchidaceae (Orchid) family, 158 species of rare orchids endemic to Java, 15 species endemic to East Java, there are 3 types of orchids typical of South Semeru, namely: Malaxis Purpureonervosa, Meleola wetteana, and Liparis rhodocila. There are Corybas fornicatus (red pearl orchid), and Macodes petola which are protected by law. The types of flora / woody plants that are easily found in Bromo Tengger National Park include: Mountain fir (Casuarina junghuhniana), Kemlandingan gunung (Albizzia lophanta), Akasia (Acacia decurrens), Quercus sp, Eupatorium pallescens, Crotalaria striata, Anaphalis java nica, Anaphalis longifolia, Adas (foeniculum vulgare, Vaccinium Varingi folium, Styphellia pungeus, Sphagum sp, Mimosa sp, Pragmatis Herba, Myrisca sp, and so on [2].

Besides flora, the potential for fauna in Bromo Tengger National Park is relatively small in terms of both number and density. Of the 15 protected mammal species, include: Manis javanica, Panthera pardus,
Hystryx branchyura, Lauricus sp, and Deer (Muntiacus muntjak), and others. Meanwhile, the Aves class that protected by law include the Java Eagle (Spizaetus Bartelsi), Bondol Eagle (Haliastur indus), Falco mauccensis, Pavo muticus, Halcyon cyanopventris, Pericrocatus miniatus, and Parus major. Overall, in Bromo Tengger National Park there are 158 species of wild animals consisting of 22 species of mammals ( 15 species protected by law, 130 species of aves ( 27 species protected by law), and 6 species of reptiles [2].

The potential for biological wealth in Bromo Tengger National Park is still not much known and interest by tourists, mainly because there is still a lack of educational media and information to visitors about the conservation of flora and fauna in their area. As stated by Yohanes Cahyo DH, S.Hut (Forest Ecosystem Controller from the Bromo Tengger Semeru National Park Center), that until now the destination of the tourists who attend is still dominated by the purpose of seeking entertainment and refreshing. The lack of information about biological wealth makes the tourists who come only consider the Mount Bromo area only as a tourist destination that displays beautiful scenery, and "instagramable". Not many tourists are aware that Mount Bromo is also a National Park, which means that Bromo is an area that functions as a support and conservation of the biological life in it. This lack of knowledge and educational media makes many tourists do not know how to behave and treat the flora and fauna in the Bromo Tengger National Park area.

From the explanation before, it can be concluded that Bromo Tengger Semeru National Park as one of the 10 Priority Destinations, has not yet developt biological potential as a tourist attraction. During the COVID-19 pandemic, such as the Bromo Tengger National Park, the number of visitors has also decreased, so an Animation Virtual Tour is needed which is not only a thirst quencher for tourists to travel, but can also be an educational medium, and an alternative to traveling in the National Park. Bromo Tengger. So in this study, researchers will analyze Stereoscopic Animation, and Virtual Tours to provide these needs. Hope that this research can be used as a reference for the Bromo Tengger Semeru National Park Center to create an alternative educational media for conservation tours.

\section{METHODOLOGY}

This research was conducted from literature studies, and discussions with stakeholders of Bromo Tengger National Park, and experts related to animation, 
stereoscopic, and virtual tours to obtain primary data. The first thing is visual storytelling, how it has the potential to support the delivery of the right message, and how the right visual storytelling is in the stereoscopic virtual tour animation content. Then the second is the potential ability of stereoscopic animation to simulate the experience and sensation of traveling. The last is how to examine the use and application of stereoscopy in various fields, especially whether stereoscopy can be deliver a message.

After the analysis process is complete and the potentials of the stereoscopic virtual tour animation are obtained, which then the approach is expected to be a reference and recommendation to the Bromo Tengger National Park Stakeholders to optimize and implement the problem to create an appropriate information and promotion media in order to maintain the existence Bromo Tengger National Park during the COVID-19 pandemic as it is today.

\section{LITERATURE STUDIES}

\subsection{Virtual Tour}

Virtual Tour is a simulation of a place that actually exists into a medium that can convey the experience. Usually the media chosen is audio-visual media such as $360^{\circ}$ images, panoramic images, sequences images, videos, with the addition of other audio-visual elements. such as sound effects, music, narration, and writing. In contrast to conventional tours, Virtual Tours usually require additional tools to access them, such as: desktop computers, smartphones, virtual reality glasses. Virtual Tour or often called "panoramic tour" indicates an unbroken view, which can be a still image or moving image arranged lengthwise so that it can be seen by rotating or shifting the viewing angle [3]. [4] Previous study on Virtual Tourism conducted describes that virtual tourism can be carried out in six forms, namely:

\subsubsection{Image}

Virtual Tour in image format is a visual medium that uses still images to convey the travel experience. This media has the aim of channeling the travel experience to its users without having to go to actual tourist locations. The message is conveyed through various languages of visual communication symbols, meaning that the message delivery process can be successful if the broadcast media can transform the experience of being on location into the right communication symbol [4].

\subsubsection{Virtual Reality Photography}

Virtual Reality Photography is a panoramic photo technique that presents an atmosphere with a spherical view. According to Dio, Safriadi, and Sukamto (2019), panoramic photos are a combination of several photos with the aim of getting photos with a wide angle of view and covering a wide view. Panoramic photos are even capable of presenting objects up to $360^{\circ}[4]$.

\subsubsection{Video}

Video is defined as a single image chunk called frames. The results of processing several images that create the illusion of moving images because the brain does not capture images individually. These videos can be accessed via television, computer, web, or via smartphone [4].

\subsection{4. $360^{\circ}$ Video}

According to Brown et al (2016), $360^{\circ}$ video is a form of Virtual Reality where the user's point of view can be spherical (round) or almost round where the center of the video is in the middle. $360^{\circ}$ video is recorded with an omnidirectional camera or through multiple cameras that can record the surroundings and each video is stitched together to form a $360^{\circ}$ video. This video can be accessed using Google Cardboard. This tool can provide users with a virtual reality experience with the help of a smartphone where users can experience, like actually being in the environment [4].

\subsubsection{Interactive Video $360^{\circ}$}

Interactive $360^{\circ}$ video is an extension of the improved $360^{\circ}$ video. Added qualities can include adding a URL (Uniform Resource Locator) to it, changing the scene via button clicks and adding special effects so that there is no visible difference in the combined videos. However, interactive $360^{\circ}$ videos are not yet widely used [4].

\subsubsection{Virtual Reality}

In Virtual Reality technology, the simulation displayed by a computer simulated environment allows users to interact with the environment they see as if they are in an actual environment, even though it is all just an imitation.

The environment in today's Virtual Reality Technology usually presents a visual experience, which is usually displayed on a stereoscopic screen 
and some sensory simulations such as sound, touch, motion, and so on. Virtual Reality (VR) is a digital space where all user movements can be known or tracked and know the surrounding picture. The results obtained are compiled and displayed to the human senses according to the movements performed. Another study conducted regarding virtual tours in Purbalingga Regency, found that virtual tours can be done through a smartphone application and obtained a feasibility test of $88 \%$ [4].

\subsection{Visual Storytelling}

Visual Storytelling is the art of communicating ideas, concepts, information correctly, in a coherent, effective manner in visual media. If described, visuals are all things related to vision, while storytelling is a way to convey a story to an audience, either in the form of words, photos, images or sound. Visual Storytelling Telling stories through a series of pictures or pictures that tell a story. In visual storytelling, the emphasis is on the visual sequence. As far as possible visuals can speak for themselves without the help of text or audio [5].

Visual Storytelling Cinema, TV, both ordinary and stereoscopic, can immediately provide a unique experience to tell a visual, but require creative creativity by creating more creative ideas. Now, the screen is no longer just showing a flat twodimensional image. In Stereoscopic, the screen being watched will only be biased, and the screen will become an open window in three-dimensional space. Objects in current stereoscopic technology can bring up or amplify the image of the depth of objects that are located behind, or in bringing the image to the front of the screen. From objects that are positioned in front of the screen window.

First-person Peripheral is term that refers to stories in which the narrator or storyteller is a supporting character in the story but not the main character. What is key to remember with stories using this point of view is that there will be experiences and scenes that happen to the protagonist of the story that the narrator will not be privy to. This approach is different from the third-person point of view in which the viewer is a "ghost" in the scene. With first-person peripheral, the viewer should be acknowledged by other characters and have some role in the narrative, though not the driving role [6].
Stereoscopic is a technique of creating or enhancing the illusion of depth and progress in a still or moving image by presenting two different images that each represent the left and right eyes of the viewer. These two two-dimensional images can then only be seen by each eye, which then the image will be translated by the human brain so as to produce a perception in and out of the screen [6]. Stereoscopic is a step-up of the illusion of depth in a photo, film, or two-dimensional image by presenting a slightly different image to each eye [7].

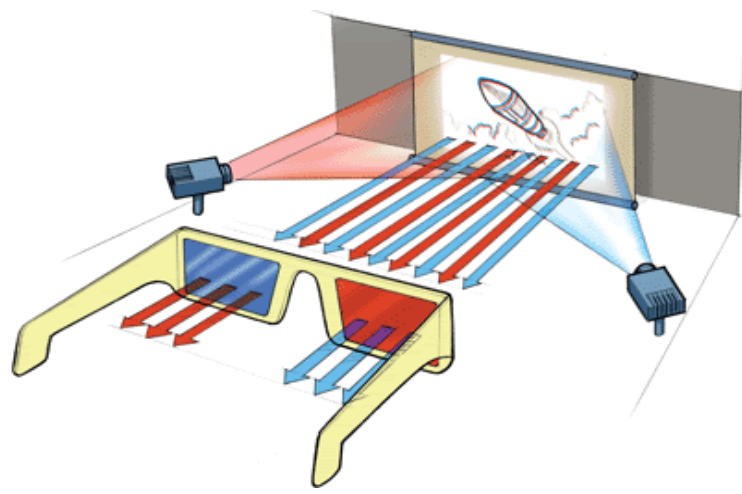

Figure 1 Anaglyph Stereoscopic Works

Traditional stereoscopic consists of a pair of 2-D images (stereograms), the easiest way to increase the depth of perception in the brain is to give the viewer's eye two different images, which represent two perspectives of the same object, with exactly the same small deviation as the perspective of the two eyes. naturally accept in binocular vision [8].

Generally, we often know stereoscopic technology in 3D Cinema and 4D Rides. In 3D Cinema, stereoscopic films are presented using a special screen and a special projector that can present side-by-side images simultaneously, and with the help of special glasses so that we can enjoy the content perfectly. In contrast to 3D cinema, Wahana 4D generally uses simpler viewing technology such advantages of other features that can make the audience feel more real by using mechanical seats, splashing water effects, and smoke effects.

\subsection{Stereoscopic}




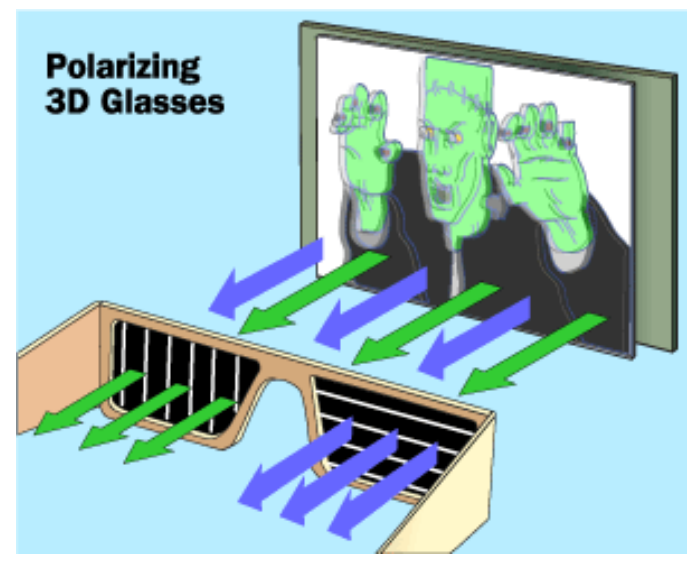

Figure 2 Polarized Stereoscopic Works

A new stereoscopic 3D film format that was recently introduced in theaters, can display images and colors with higher quality than before. Unlike the old stereoscopic technology that has been used previously, namely anaglyph which separates the right-left image by changing the color to red-blue, this new technology utilizes a projector lens and polarized glasses, a screen made of metalized material, which allows the viewer to capture a visual image. more detailed and sharp, clearer colors [8].

The documented application of stereoscopic technology in the world of science education began in 1838. Sir Charles Wheatstone, a physicist and inventor from England, designed stereoscopic to describe how binocular parallax works in the human visual system. After his discovery, he explained how stereoscopic could be used in science education. Then a comprehensive review of the early history of stereoscopic technology continues until the invention of stereoscopic film technology. And after that, stereoscopic technology is most often applied as a marketing gimmick in the entertainment world [10].

Stereoscopic blockbusters such as 2009's Avatar, which is currently the highest grossing film of all time which had previously revived the overwhelming interest in stereocopic in the public, are now showing a decline that can be seen from a trend that shows as 3D movie ticket sales have decreased over the past few years. four consecutive years in total revenue and seven consecutive years in overall ticket sales percentage worldwide, and sales of stereoscopic home theater systems have also fallen below industry expectations [10].

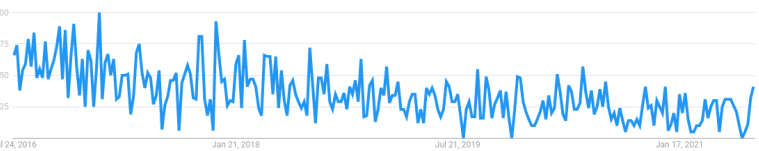

Figure 3 "Stereoscopic 3D" interest from 2016 to 2021

Stereoscopic technology is also used to aid learning in the education and training of pilots, surgeons and drivers. In other science education, this technology is also used to support learning astronomy, geography, geology, and geophysics. The most popular GeoWall in education The most popular stereoscopic application in education is "GeoWall", a tool that can project stereoscopic images using a computer and two projectors, and this technology has been used and utilized by many formal and informal educational institutions as a medium of knowledge, training and research [10].

\section{RESULT AND DISCUSSION}

From the literature study that has been discussed previously, each broadcast format that can be applied to a virtual tour has many advantages, one of which is a stereoscopic $360^{\circ}$ video that can provide an immersive experience to the audience. The immersive view gives the viewer the freedom to see the environment in all directions so that the audience will feel that they are directly involved in the story. The advantages of stereoscopic in giving the impression of the story, and the experience of watching the audience more than those that are not in stereoscopic format. The advantages possessed by the stereoscopic format are suitable to be applied to virtual tour media, so that if these technologies are combined together, they will add to the sensation and experience compared to virtual tours with other formats.

The use of stereoscopic technology in virtual tours will not be enough if the visual storytelling style used is not appropriate. Generally, Stereoscopic and Virtual Tour formats are presented using a POV (Point of View) shooting angle technique or in the game commonly called First Person. Point of View is a point of view in a story that is taken from the view of one of the characters/actors in the story itself. However, Point of View, has several shortcomings, one of which is the difficulty of conveying the message and storyline. With these shortcomings, the author needs to add a 2 nd character as a messenger or message. This technique is commonly called the First-person Peripheral visual storytelling technique. 
With these factors, the application of a stereocopic animated virtual tour allows the audience to feel the sensation of traveling without having to travel, so that creators can use this feeling to insert messages with the aim of solving problems that have been difficult to do in actual locations such as travel etiquette, education about Flora and fauna. This alternative is considered very appropriate to be presented during the Covid-19 pandemic which limits people's mobility, especially in terms of traveling as it is today.

\section{CONCLUSION AND SUGGESTION}

\subsection{Conclusion(s)}

After identifying problems, implementing and studying literature, it can be concluded that the advantages in stereoscopic techniques and technology, and animation can be used and utilized to support virtual tour content to increase the sensation of the traveling experience without having to go to the actual location. Traveling without having to go to a real location with virtual tour media will be able to help people who want to travel but are hampered by the COVID-19 pandemic, so people don't need to leave their homes and help the government in preventing the spread of the COVID-19 virus.

\subsection{Suggestion(s)}

Suggestions for developing virtual tours by utilizing animation techniques, and Stereoscopic technology can be used as a policy basis for the central government, local governments, tourism agencies as an alternative solution to attract tourists during the COVID-19 pandemic in Bromo Tengger National Park. In addition to being an entertaining and attractive entertainment medium, this stereoscopic animated Virtual Tour is also expected to be the right medium in conveying information and education that has been difficult to convey in actual locations such as how to behave in actual tourist locations, information about spots that are allowed and not allowed. for camping, and information about flora and fauna in Bromo Tengger Semeru National Park. After this Stereoscopic Virtual Tour Animation can be actually used, it is hoped that it can be an example and inspiration for other tourist locations who are looking for solutions to develop tourism during this covid-19 pandemic.

\section{REFERENCES}

[1] COVID-19 Data Repository by the Center for Systems Science and Engineering (CSSE) at Johns
Hopkins University [ cited 2021 July 13]. https:/github.com/CSSEGISandData/COVID-19

[2] B. Rudi, Y.D. Sari, A. Setiyawati, P. Supriyandogo, Sutini. Information Book of Bromo Tengger Semeru National Park.; 2015

[3] S. Vidiardi, Pengembangan Museum Virtual Interaktif Menggunakan Teknologi Desktop Virtual Reality Pada Museum Ranggawarsita, Skripsi, Pendidikan TITK, Jurusan Teknik Elektro Fakultas Teknik Universitas Negeri Semarang, 2015.

[4] R. Muhammad, D. Mutiarin, J. Damanik. Virtual Tourism Sebagai Alternatif Wisata Saat Pandemi.; 2021

[5] Handout Visual Story Telling. [ cited 2021 July 22]. https://ocw.upj.ac.id/files/Handout-VCD204-Handout-Visual-Story-Telling.pdf

[6] J. Bucher. Storytelling for Virtual Reality, Methods and Principles for Crafting Immersive Naratives, 2018

[7] H. Barton, K. Byrne, PDF, Introduction to Human Vision, Visual Defects \& Eye Tests, p. 22,2007

[8] A. Bhatti, 2008, Stereo Vision, Book, ISBN 978-953-7619-22-0, pp. 372, I-Tech, Vienna, Austria.

[9] J. Hart, 2004, Chapter 1 : Basic Principles of 3D Photography \& The Slide-Bar.

[10] C.A. Price, H-S. Lee, Julia D.Plummer, M. S. Rao, R. Wyatt. Position Paper on Use Of Stereoscopy to Support Science Learning: Ten Years Of Research.; 2015 